\title{
MODELLING OF EMC BROADBAND ANTENNAS WITH COMPLEX GEOMETRY ABOVE 1 GHz
}

\author{
Tereza Novakova, Mikulas Bittera, Viktor Smiesko \& Eva Kralikova
}
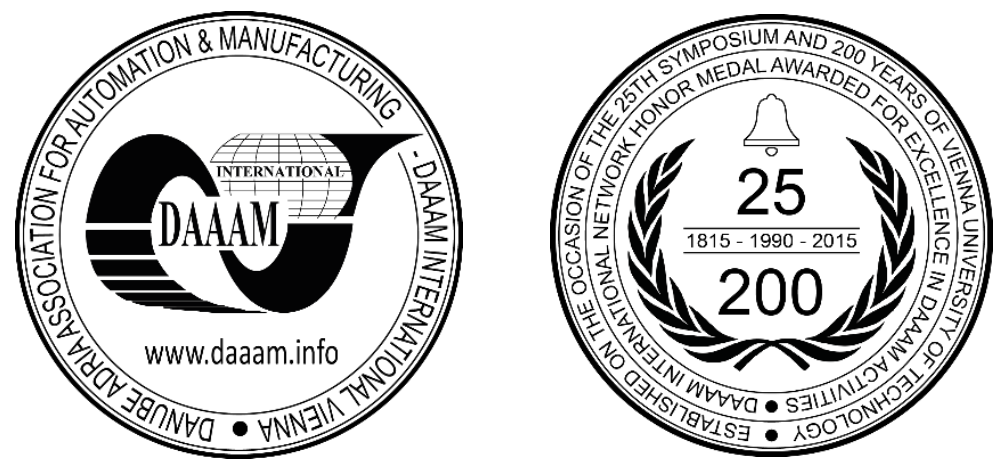

This Publication has to be referred as: Novakova, T[ereza]; Bittera, M[ikulas]; Smiesko, V[iktor] \& Kralikova, E[va] (2016). Modelling of Emc Broadband Antennas With Complex Geometry Above $1 \mathrm{GHz}$, Proceedings of the 27th DAAAM International Symposium, pp.0363-0370, B. Katalinic (Ed.), Published by DAAAM International, ISBN 9783-902734-08-2, ISSN 1726-9679, Vienna, Austria DOI: $10.2507 / 27$ th.daaam.proceedings.054

\begin{abstract}
Radiofrequency measurements of electromagnetic compatibility are negatively influenced by uncertainty of the measuring antenna. To make quantification of errors caused by the antenna faster, it is useful to create an antenna model and simulate the circumstance. A change in parameter values caused by a change of position of the antenna or a change of surroundings can be determined using a numerical electromagnetic simulation software. Modelling a precise copy of antenna, however, can cause unnecessarily high simulation requirements, therefore it is essential to know how model structure simplification affects the characteristics of the model. For this purpose, broadband antennas commonly used for measurements of electromagnetic compatibility above $1 \mathrm{GHz}$ were taken into account: stacked logarithmic-periodic antenna and double-ridged horn antenna. Multiple models were created with various extent of simplification to achieve reduction in computational time and memory requirements. The level of correspondence of the model to the real antenna was inspected, using chosen electromagnetic simulation software, by obtaining characteristic parameters of the models, i.e. antenna factor, gain, and radiation pattern, and by comparison of results to measured values. Considering the results and computational effort of the simulation, the most suitable model was chosen for each antenna.
\end{abstract}

Keywords: Broadband antenna; Antenna model; Feature selective validation; Stacked logarithmic-periodic dipole array; Double-ridged horn antenna.

\section{Introduction}

Numerical simulators have become widely used to solve problems in electromagnetism, since it is very difficult to solve the problems analytically for unsymmetrical and inhomogeneous structures [1,2,3]. When simulating complex antennas, one can come to a point, when the simulation requirements are higher than the computational power of the computers available for computation. In such case, it is very important to know the right approach to modelling, to be able to create a simulation model that copies the real problem at full, but simultaneously does not demand excessively on the computational power and simulation time [2].

This paper is focused on the choice of the optimal model of broadband antennas with complex geometry that are commonly used in measurements of electromagnetic compatibility for frequency range above 1 GHz. To analyse the models' characteristic parameters, e.g. antenna factor, gain, and radiation pattern, numerical simulator FEKO was used. 
Characteristic parameters of each model were then compared to measured values and their agreement was validated as a comparison of two data sets using feature selective validation method.

\section{Problem analysis}

Solving difficult problems in electromagnetism can be done experimentally, analytically, or numerically. Numerical methods, as the most practical way of solving these problems, can be divided into three main categories: frequency domain, time domain and eigenmode or modal solvers, while the most suitable methods are solvers in frequency domain [4]. They generally solve Maxwell's equations in their integral form [5]:

$$
\iiint_{V} \nabla X d x d y d z=Y
$$

where $Y$ is the source, $X$ is the unknown function, $V$ is the volume of the analysed area, and $\nabla$ is the Hamiltonian operator. Frequency domain solvers discretize the solution domain, build a matrix, invert the matrix and use iteration to find the solution $X[5]$ :

$$
X=\left[f_{n}\right]\left[l_{m n}^{-1}\right]\left[g_{m}\right]
$$

where $f_{\mathrm{n}}$ are the basis functions, $g_{m}$ are the exciting functions, and $l_{m n}$ are the linear operators. The matrix building and its solution must be repeated for each frequency.

Numerical method has to be chosen in regard to the type of application for which it is used and requires some level of compromising. The method used in this work, Method of Moments (MoM), was chosen and tested in previous work and is described in [6]. The simulations were carried out in electromagnetic fields simulator FEKO, which uses MoM in combination with other auxiliary methods, such as Finite Element Method, Finite Difference Domain Method, etc. [7]. Model surface can be discretised into mesh using simple wire segments or triangles.

After retrieving the simulation results, validation is an important step to quantify the comparison of result data sets. For this purpose, Feature Selective Validation (FSV) has been used, which quantifies the comparison by mirroring engineers' visual perception and allows for automated comparisons of large complex data [8]. The data comparison is based on decomposing the original data into two component measures and subsequent recombination of the results to provide a global goodness of fit measure [9]. FSV offers three means of the data comparison [10]:

- Amplitude difference measurement (ADM) - comparison of the amplitudes and 'trends' of the two data sets

- Feature difference measurement (FDM) - comparison of the rapidly changing features as a function of independent variable

- Global difference measurement (GDM) - combination of the previous two

GDM can be expressed as:

$$
G D M=\sqrt{A D M^{2}+F D M^{2}}
$$

The resulting values can be divided into six natural language descriptor categories, ranging from Excellent to Very Poor. In [11], FSV validation has been presented for computational electromagnetics modelling and simulation.

Previous works that analysed and validated the effect of model accuracy on simulation results for logarithmicperiodic dipole array and hybrid biconical-logarithmic-periodic dipole array are in [4] and [12]. The accuracy of the model dimensions and shape has considerable impact on simulation results. To analyse the extent of this impact further, two geometrically different broadband antennas were taken into account and models were created.

\subsection{Modelled antennas}

First analysed, stacked logarithmic-periodic array, further denoted as STLP, consists of four identical arms. Two pairs of arms are placed to form a $\mathrm{V}$-shape in order to obtain a higher degree of directivity than observed in standard logarithmic-periodic antennas [13]. The STLP antenna consists of a $1 \mathrm{~mm}$ thick metal plate with $2 \times 20$ dipole pairs, with the shortest and longest dipole element length being $8 \mathrm{~mm}$ and $95 \mathrm{~mm}$ respectively. Length of the antenna in the direction of the main lobe is $244 \mathrm{~mm}$. The scale factor is 0.87 and spacing factor 0.21 .

Another analysed, a double-ridged horn antenna, further denoted as DRGH, has an aperture dimensions of $243 \mathrm{~mm} \times 155 \mathrm{~mm}$ and the length in the direction of the main lobe is $210 \mathrm{~mm}$. In general, horn antennas are strongly influenced by imperfections in manufacturing process. Even a slight deviation from intended dimensions and shape, mainly in the feeding structure of the antenna, can lead to significant change in characteristic parameters of the antenna [14]. As a consequence, also the simulation model has to be very precise, to obtain satisfactory results. 
Both STLP and DRGH antenna are used for applications in frequency range $1 \mathrm{GHz}-18 \mathrm{GHz}$ and are widely used in electromagnetic compatibility testing of devices.

\subsection{Simulation models}

To create most of the models, CAD module of FEKO simulator was used. Two different models of STLP antenna were created, which are shown in Fig. 1:

- Surface model - omitting the thickness of the material, with expectation of shorter simulation time and lower computational requirements (Fig. 1.a);

- Volume model - respecting $1 \mathrm{~mm}$ thickness of metallic material, with expectation of more accurate results (Fig. 1.b).
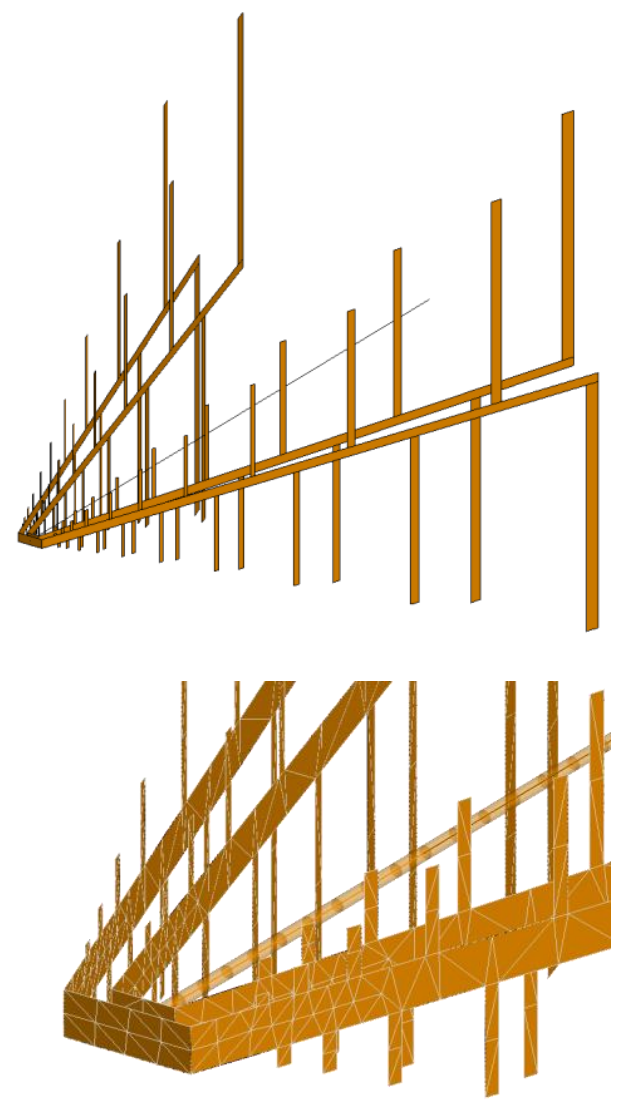

a)
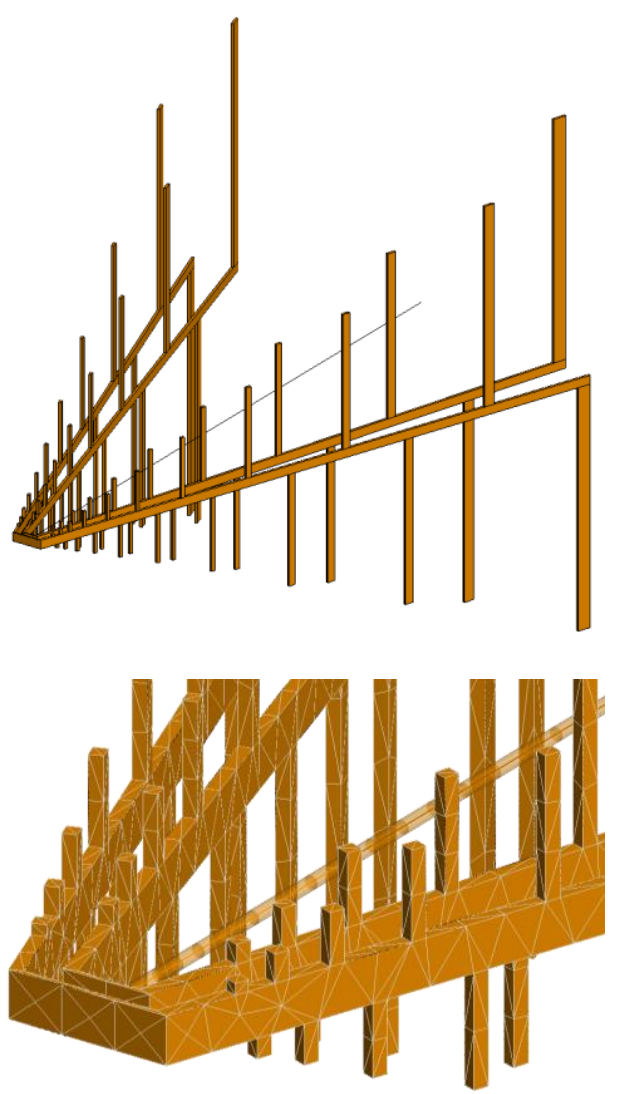

b)

Fig. 1. STLP antenna models: (a) surface and (b) volume, without mesh (up) and detailed with mesh (down)

For DRGH antenna, three different models were created, as seen in Fig. 2:

- Surface model - omitting thickness of the horn, omitting perforated side walls, resonator measured and modelled manually, with expectation of shorter simulation time and lower computational requirements (Fig. 2.a)

- Scan model - a precise model obtained by 3D scanning, with expectation of more accurate results (Fig. 2.b)

- Combined model - a combination of previous two - precise scanned resonator, omitted perforated side walls and material thickness, expected reduction in simulation time and computational requirements, while sustaining satisfactory results (Fig. 2.c) 

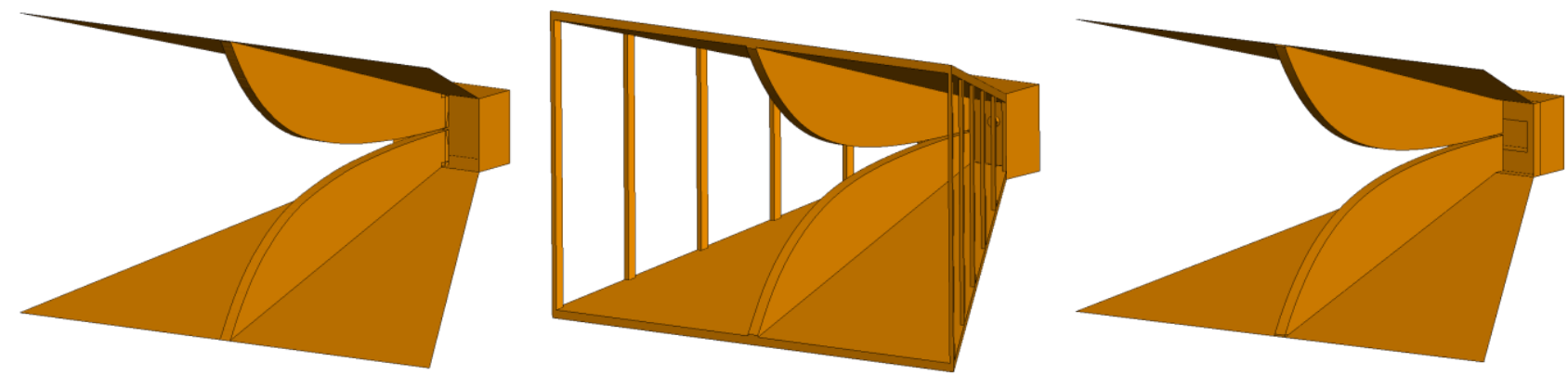

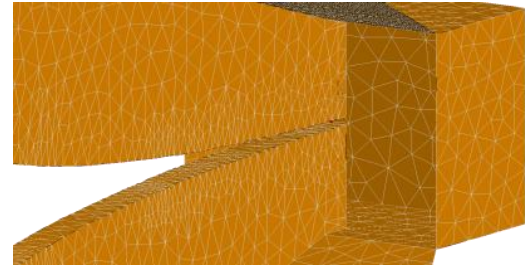

a)

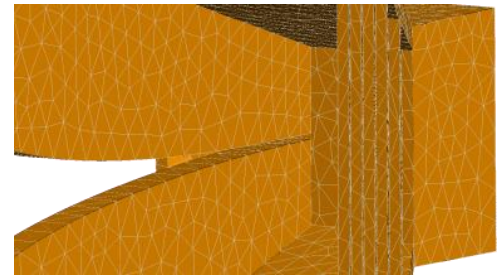

b)

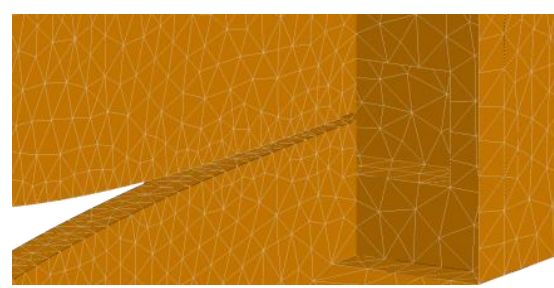

c)

Fig. 2. DRGH antenna models: (a) surface; (b) scan; (c) combined, without mesh (up) and detailed with mesh (down)

Scan model of DRGH antenna does not contain inner structure behind resonators, which was inaccessible for the optical 3D scanner and was also omitted in surface model for the matter of comparison. All three models of DRGH do not contain feeding part of the antenna, as it was inaccessible without dismantling, which would mean a risk of permanent damage to the antenna.

\section{Results}

For both antennas, three characteristic parameters were obtained, analysed, and validated: antenna factor, gain and radiation pattern. For each model, the three parameters were obtained in the antennas' intended frequency range, $1 \mathrm{GHz}$ $-18 \mathrm{GHz}$, and compared to the measured values.

Antenna factor is roughly described as the extent, at which an antenna can transform an electric field it is placed in to voltage. As the most important parameter of an antenna, antenna factor was obtained using known values of electric field radiated from a source at a known distance and the induced antenna voltage, then computed using near-field analysis in FEKO. Measured values of antenna factor were obtained by three-antenna method following the international standard [15].

Gain, a parameter described as radiated field strength in specific direction, which may be expressed relative to radiation of a theoretical isotropic radiator or dipole in the same direction, was obtained using far-field analysis. Gain value is achieved by pattern alternation (directivity), but antenna losses are subtracted. Only the value in the direction of maximum radiation was considered. Measurement of gain was performed also by three-antenna method at the measuring distance of $3 \mathrm{~m}$.

Radiation pattern, described as radiated electric field strength as a function of azimuth and elevation, was also computed using far-field analysis. Measurement of radiation pattern was performed in anechoic chamber, which has to be fully anechoic to avoid the influence of the surroundings on the results.

\subsection{STLP antenna}

As seen in Tab. 1, volume model of STLP antenna shows more satisfactory results, reaching GDM value of 0.144 for antenna factor and 0.593 for gain, while surface model shows GDM values of 0.179 for antenna factor and 0.717 for gain. Comparison of models' results to measured values is shown in Fig. 3.a for antenna factor and Fig. 3.b for gain.

\begin{tabular}{|c|c|c|c|c|c|c|}
\hline & \multicolumn{3}{|c|}{ Antenna factor } & \multicolumn{3}{c|}{ Gain } \\
\hline Model type & ADM & FDM & GDM & ADM & FDM & GDM \\
\hline Surface & 0.080 & 0.153 & 0.179 & 0.370 & 0.522 & 0.717 \\
\hline Volume & 0.073 & 0.110 & 0.144 & 0.343 & 0.409 & 0.593 \\
\hline
\end{tabular}

Table 1. STLP antenna models: ADM, FDM, and GDM values of antenna factor and gain 


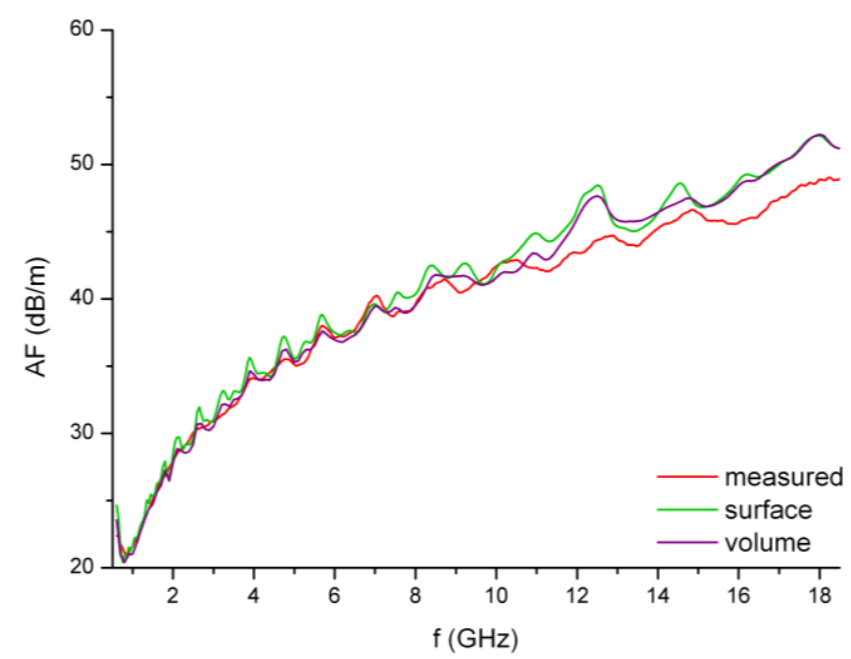

a)

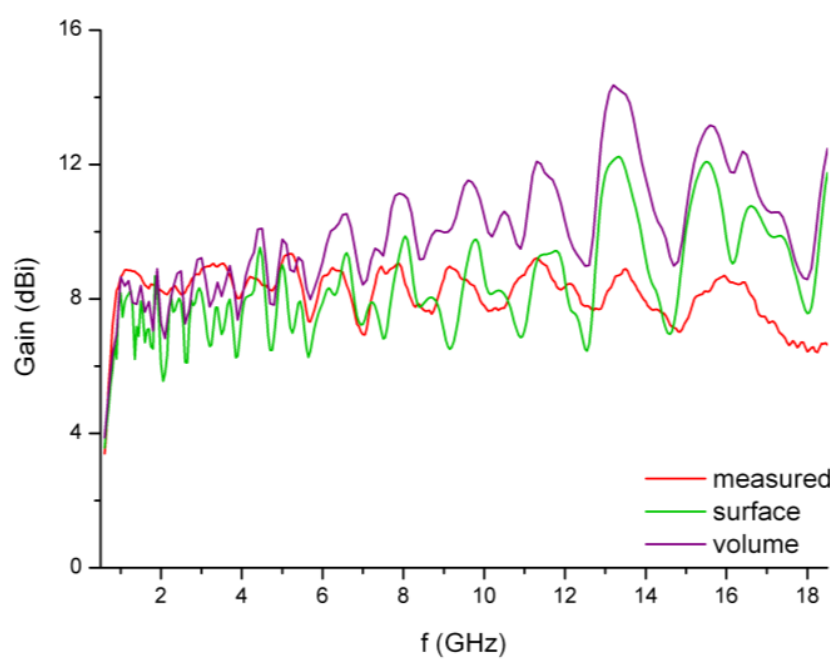

b)

Fig. 3. STLP antenna: Comparison of (a) antenna factor and (b) gain of analysed models to measured values

Both surface and volume model exhibit relatively good agreement of radiation pattern trace in the main lobe, as seen in Fig. 4 for $14 \mathrm{GHz}$ in E-plane and H-plane.

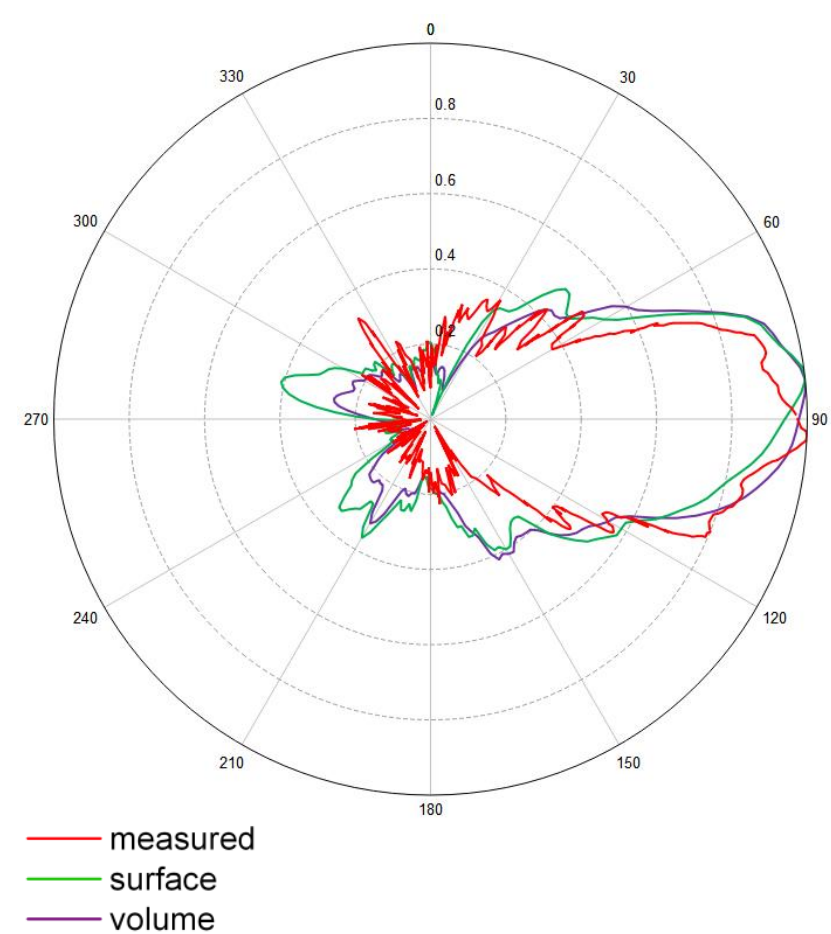

a)

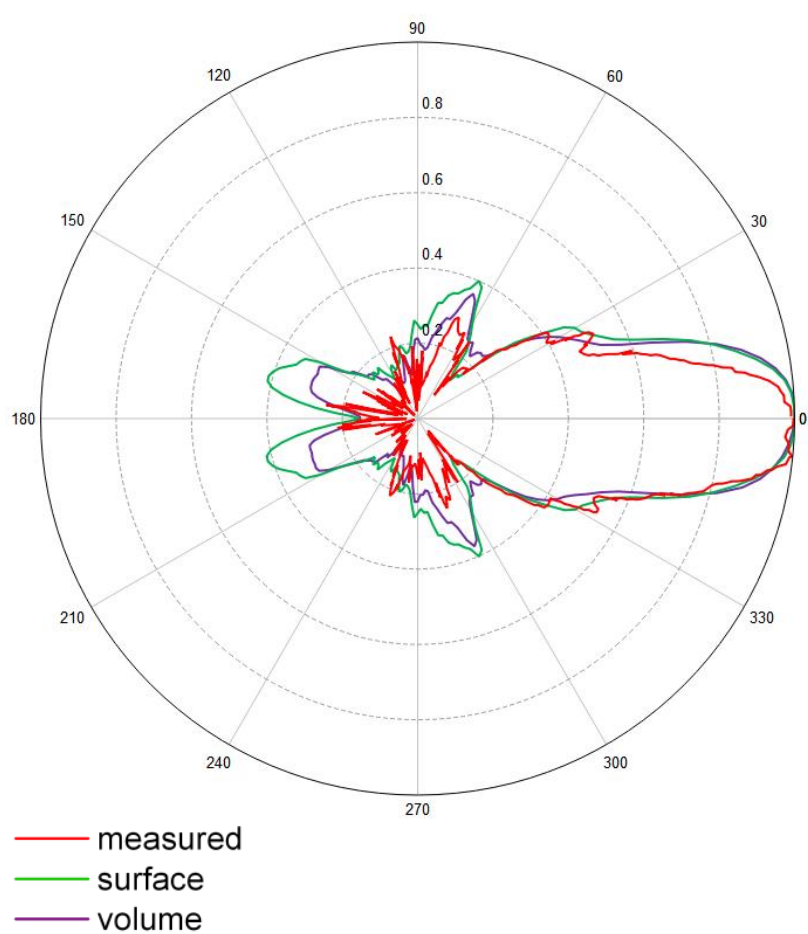

b)

Fig. 4. STLP antenna: Comparison of radiation pattern of different models to measured values in (a) E-plane and (b) H-plane at $14 \mathrm{GHz}$

To select the most suitable model, not only the simulation results are important, but also the memory size required by computation process and the overall simulation time have to be taken into account. Tab. 2 shows the difference in simulation parameters and the increase of required time and memory caused by different structure of the model. 


\begin{tabular}{|c|c|c|c|c|c|}
\hline Model type & $\begin{array}{c}\text { Simulation } \\
\text { time }\end{array}$ & $\begin{array}{c}\text { Number of } \\
\text { triangular } \\
\text { segments }\end{array}$ & $\begin{array}{c}\text { Number of } \\
\text { wire } \\
\text { segments }\end{array}$ & $\begin{array}{c}\text { Required } \\
\text { memory } \\
\text { RAM }\end{array}$ & $\begin{array}{c}\text { Evaluation matrix } \\
\text { size }\end{array}$ \\
\hline Surface & $813 \mathrm{~s}$ & 1220 & 55 & $16.97 \mathrm{MB}$ & $1390 \times 1390$ \\
\hline Volume & $14882 \mathrm{~s}$ & 4788 & 55 & $426.39 \mathrm{MB}$ & $7399 \times 7399$ \\
\hline
\end{tabular}

\subsection{DRGH antenna}

Table 2. STLP antenna models: Simulation parameters

Validation results of DRGH antenna are generally less satisfying than those of STLP antenna, both surface and scan model show relatively high values of GDM for antenna factor, that is 0.372 and 0.310 respectively, whereas the values of GDM for gain are as high as 1.260 and 1.350. For combined model, the GDM values are improved to 0.137 for antenna factor and 0.651 for gain. For surface and scan model, the resulting antenna factor and gain trace, shown in Fig. 5.a and Fig. 5.b, suffer from significant deviation seen as undesired peaks at several frequencies.

This may be due to imperfections in the model geometry, primarily imprecise resonator curve in surface model and missing inner part behind the resonators of both models.

This phenomenon is overcome in combined model, consisting of the precise resonator curve and the inner structure. This model, however, maintains visible deviation in both antenna factor and gain trace increasing at higher frequencies.

\begin{tabular}{|c|c|c|c|c|c|c|}
\hline & \multicolumn{3}{|c|}{ Antenna factor } & \multicolumn{3}{c|}{ Gain } \\
\hline Model type & ADM & FDM & GDM & ADM & FDM & GDM \\
\hline Surface & 0.212 & 0.372 & 0.450 & 0.687 & 0.990 & 1.260 \\
\hline Scan & 0.186 & 0.310 & 0.377 & 0.671 & 1.050 & 1.356 \\
\hline Combined & 0.077 & 0.109 & 0.137 & 0.445 & 0.454 & 0.651 \\
\hline
\end{tabular}

Table 3. DRGH antenna models: ADM, FDM, and GDM values of antenna factor and gain

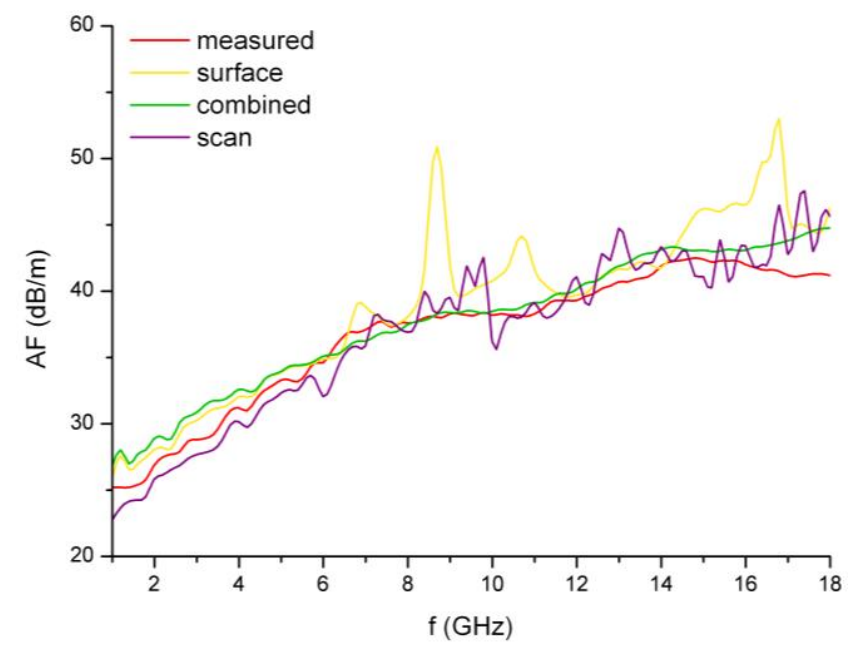

a)

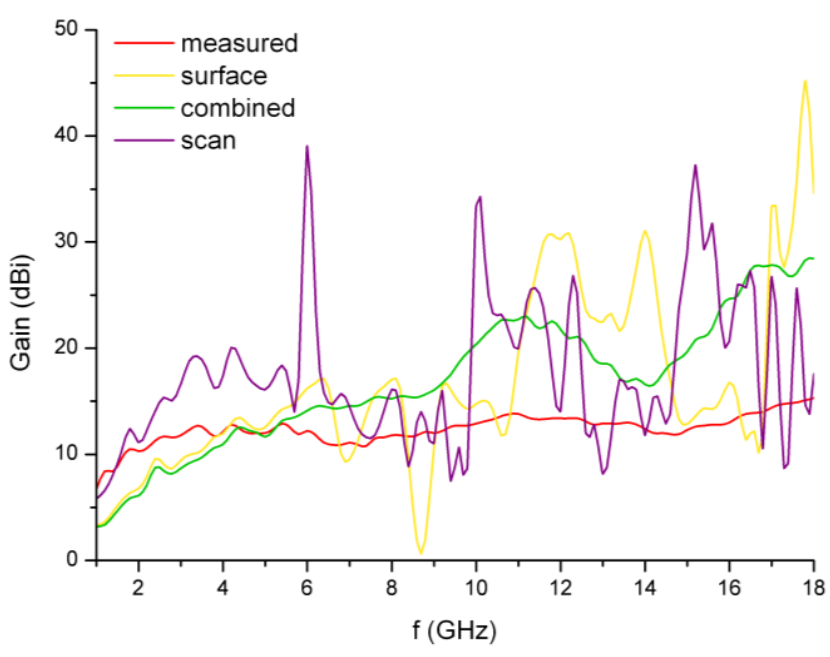

b)

Fig. 5. HORN antenna: Comparison of (a) antenna factor and (b) gain of analysed models to measured values

Models show fair to good agreement in radiation pattern in the main lobe, as seen in Fig. 6 for $14 \mathrm{GHz}$. Similarly as for gain trace, both surface and scan model fail at several frequencies showing poor accuracy of radiation pattern compared to measured values. 


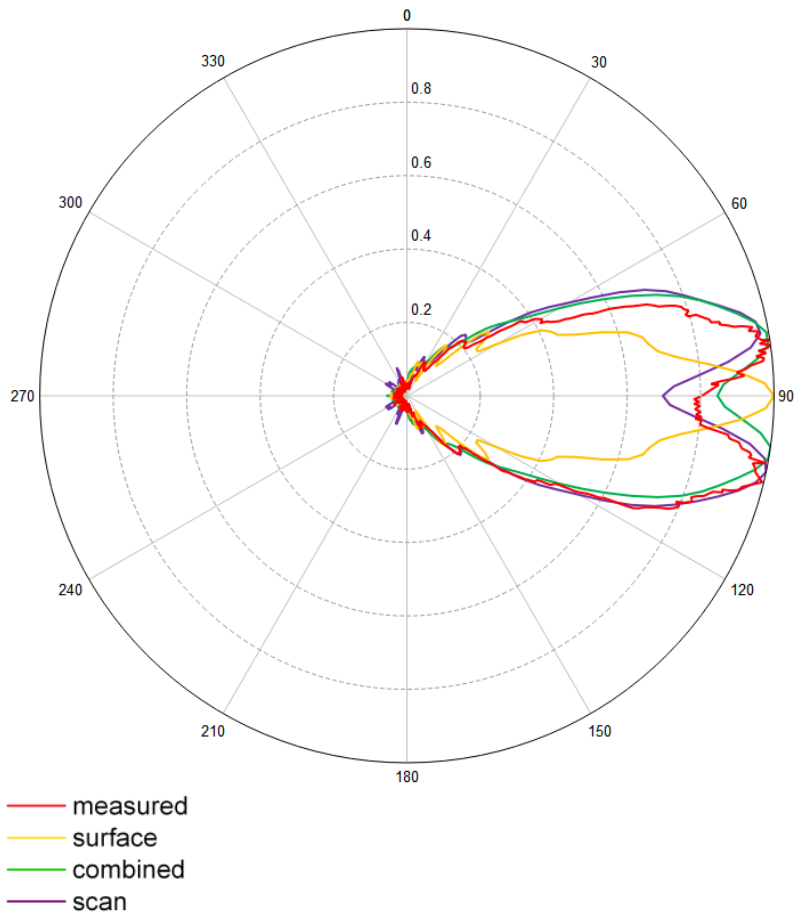

a)

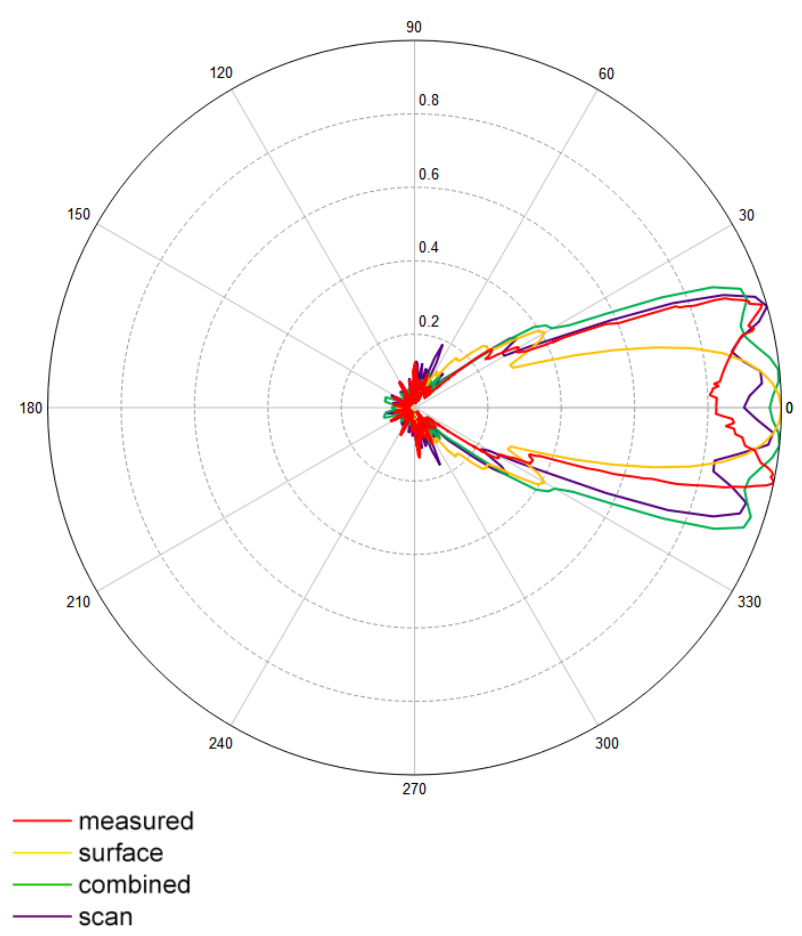

b)

Fig. 6. DRGH antenna: Comparison of radiation pattern of different models to measured values in (a) E-plane and (b) H-plane at $14 \mathrm{GHz}$

The final simulation parameters for DRGH antenna are given in Tab. 4. In the case of DRGH antenna, not only the results, but also the simulation parameters are markedly improved in combined model, which is caused by simplification of resonator curve surface and replacement of bulk walls of the horn with simple surface walls.

\begin{tabular}{|c|c|c|c|c|c|}
\hline Model type & $\begin{array}{c}\text { Simulation } \\
\text { time }\end{array}$ & $\begin{array}{c}\text { Number of } \\
\text { triangular } \\
\text { segments }\end{array}$ & $\begin{array}{c}\text { Number of } \\
\text { wire } \\
\text { segments }\end{array}$ & $\begin{array}{c}\text { Required } \\
\text { memory } \\
\text { RAM }\end{array}$ & $\begin{array}{c}\text { Evaluation matrix } \\
\text { size }\end{array}$ \\
\hline Surface & $33334 \mathrm{~s}$ & 9000 & 13 & $1.37 \mathrm{~GB}$ & $13476 \times 13476$ \\
\hline Scan & $80165 \mathrm{~s}$ & 13092 & 13 & $2.89 \mathrm{~GB}$ & $19629 \times 19629$ \\
\hline Combined & $29245 \mathrm{~s}$ & 8286 & 13 & $1.16 \mathrm{~GB}$ & $12411 \times 12411$ \\
\hline
\end{tabular}

Table 4. DRGH antenna models: Simulation parameters

\section{Conclusion}

In practical applications, there are times when duration of the simulation and memory requirements of an antenna model exceed tolerable extent. With simplification of the model structure however, the accuracy of the model parameters decreases. When choosing the right type of a model, it is important to find a compromise.

For STLP antenna, both models, surface and volume, show relatively similar results, although the simulation parameters are much more favourable for surface model, where simulation time and the memory requirements are almost 20-times lower. Therefore, the surface model omitting thickness of the metallic material may be more suitable for use in practical applications.

As for DRGH antenna, the only model showing good resemblance of characteristic parameter values compared to measured values is combined model. This confirms the expected need of high precision of model dimensions in the resonator and inner structure part of the antenna, while at the same time, the model keeps lowest simulation requirements at as much as $1 / 3$ of the time and memory required by scan model. Replacing the horn walls with simple surface and completely omitting perforated side walls has no significant effect on model parameters.

However, omitting detailed feeding part of the antenna might be the reason for the significant deviation, which is the field of interest for further study to acquire even better results while preserving low simulation and memory requirements. 


\section{Acknowledgements}

The work presented in this paper was supported by the Slovak Grant Agencies of Ministry of Education, Science, Research and Sport of the Slovak Republic VEGA, No. 1/0431/15 and Slovak Research and Development Agency APVV, No. APVV-15-0062.

\section{References}

[1] Cicchetti, R., Testa, O. \& Caratelli, D. (2012). A numerical procedure for the analysis of EMC/EMI problems in radio communication systems operating in complex environment, In: IEEE Transactions on Electromagnetic Compatibility, vol. 54, no. 6 (December 2012), pp. 1269-1280.

[2] Ndip, I., et. al. (2012). Modelling the shape, length and radiation characteristics of bond wire antennas, In: IET Microwaves, Antennas \& Propagation, vol. 6, no. 10 (July 2012), pp. 1187-1194.

[3] Matyas, J., Vlcek, K. (2011). Experimental antenna design based on natural construction. Proceedings of $22^{\text {th }}$ DAAAM international symposium on Intelligent manufacturing and automation, Zadar, Croatia, vol. 22 (2011), ISSN 1726-9679, Katalinic, B. (Ed.), pp. 1435-1436, DAAAM International, Vienna

[4] Bittera, M. (2013). Modeling broadband wire antennas with complex geometry. Proceedings of $24^{\text {th }}$ DAAAM international symposium on Intelligent manufacturing and automation, Procedia engineering, Zadar, Croatia, vol. 69 (2014), ISSN 1877-7058, Katalinic, B. (Ed.), pp. 1082-1087, Elsevier, doi:10.1016/j.proeng.2014.03.094

[5] Duffy, A., et. al. (2005). The feature selective validation (FSV) method, In: IEEE International Symposium on EMC, Chicago, (August 2005), ISSN 2158-1118, pp. 272-277

[6] Harrington, R.F. (1993) Field computation by moment method, Wiley-IEEE Press, ISBN 0-7803-1014-4, New York

[7] http://www.altairuniversity.com/wp-content/uploads/2015/03/UserManual.pdf, (2015). FEKO 7.0 User's Manual, EM Software and Systems-S-A, Accessed on: 2016-05-02.

[8] http://ing.univaq.it/uaqemc/FSV_4_0_3L/1DFSV_Manual.pdf, (2007). 1D FSV Tool, User's Guide, Version: 4, Accessed on: 2016-07-02

[9] Hartansky, R. \& Hallon, J. (2016). Sensors for electromagnetic field measurements, STU, ISBN 978-80-227-45659, Bratislava

[10] IEEE 1579.1 (2009). Standard for validation of computational electromagnetics computer modeling and simulation, IEEE Standard

[11] Harrington, R. F. (1993). Field computation by moment methods, first ed., Wiley, ISBN: 978-0-7803-1014-8, New York

[12] Bittera, M., Stih, M. (2009). Modelling of wire antennas, In: Mechatronika 2009: Proceedings of $12^{\text {th }}$ International Conference on Mechatronics, Trencianske Teplice, Slovak Republic, 3-5.6.2009, Trencin: Trencianska univerzita Andreja Dubceka v Trencine, 2009, ISBN 978-80-8075-392-4, pp. 73-76

[13] Kraus, D. P. (2001). Antennas, Third ed., ISBN 0-07-123201-X McGraw-Hill Education, Singapore

[14] Jacobs, B., Odendaal, J. W. \& Joubert, J. (2009). Modelling manufacturing tolerances in 1-18 GHz double-ridged horn antennas, In: $39^{\text {th }}$ European Microwave Conference, Rome, 2009, ISBN 978-1-4244-4748-0, pp. 1484-1487

[15] ANSI C63.5 (2006). American national standard for calibration of antennas used for radiated emission measurements into electromagnetic interference, American National Standard 